\title{
Analysis of radiomorphometric indices in postmenopausal patients with osteoporosis: Case report and literature review
}

\author{
Ioana Madalina Lescai ${ }^{1,2}$, Laurenta Lelia Mihai ${ }^{3}$, Monica Mihaela Cirstoiu ${ }^{4,5}$ \\ ${ }^{1}$ Doctoral School, "Carol Davila" University of Medicine and Pharmacy, Bucharest, Romania \\ ${ }^{2}$ Blident Help Dental Clinic, Bucharest, Romania \\ ${ }^{3}$ Department of Periodontology and Oral Pathology, "Titu Maiorescu" University, Bucharest, Romania \\ 4"Carol Davila" University of Medicine and Pharmacy, Bucharest, Romania \\ ${ }^{5}$ Department of Obstetrics \& Gynaecology, Emergency University Hospital, Bucharest, Romania
}

\begin{abstract}
Objectives. The aim of this case report is to present a single patient case superimposed on the literature knowledge in regard to mophometric mandibular variations observed on dental panoramic radiography and used to identify patients with low bone mass density (BMD).

Case presentation. A 62 years old female patient reported to the Blident Help Dental Clinic, for specific visits and treatments, 3 years apart. Based on the digital panoramic radiography and DXA measurement, an osteoporosis evaluation with radiomorphometric indices was performed.

Values for maximum condylar height, maximum coronoid height, projective height of the mandibular ramus, minimum ramus breadth and antegonial angle are higher on both sides. the values decreased for gonial angle, gonial index, mandible cortical width (MCW), superior and inferior mental height and panoramic mandibular indices on both sides. Bigonial distance also dicreased and the mandibular cortical index ( $\mathrm{MCl})$ changed from $\mathrm{C} 2$ category in 2017 to C3 category in 2020.

Discussions. This postmenopausal pacient had a decline in MCW values which were lower than $3 \mathrm{~mm}$ (threshold to differentiate normal) on panoramic radiographs of women with low BMD. Antegonial Index had a decreased value and could be used as a prediction index for osteoporosis. $\mathrm{MCl}$ index changed from $\mathrm{C} 2$ to $\mathrm{C} 3$ in correlation with the changes of bone mass density in lumbar spine.

Conclusions. $\mathrm{MCl}, \mathrm{MCW}$, antegonial index and bone density played an important role in determining significance of effects of lower BMD at postmenopausal on the mandibular ramus region.
\end{abstract}

Keywords: postmenopause, radiomorphometric indices, osteoporosis

\section{INTRODUCTION}

Osteoporosis is a systemic disease that is considered a public health problem due to its social impact. The disease is altering the bone structure and causes a decrease in bone mineral density (BMD), which increases bone fragility and susceptibility to fractures. Although dual X-ray absorptiometry (DXA) is considered the gold standard for the assessment of BMD, analysis of multiple radiomorphmetric indices has been performed to identify low BMD predictors. BMD predictors may play an important role in examinations by dentists to properly monitor bone density measurements for low BMD and osteoporosis assessments.

There is a wealth of research in the field of dentistry investigating whether panoramic radiography can be applied to identify patients at risk for reduced bone mass and osteoporosis. This would allow dentists to make aware patients of the possible underlying treatment and to present this risk before the pacient suffers any fracture.

The mandible, like other bones, is one of the bones in the body that is affected by aging and changes in metabolic function and hormonal disor- 
ders. To forensic medicine, the mandible is considered a good indicator for distinguishing changes in tooth or bone morphology and sexuality by gender and age (gonial angle, mandibular index, panoramic index) of bones affected with osteoporosis (especially postmenopausal women). The height and depth of the ramus may vary depending on age and as a result of hormonal disturbances and dental status [1].

A commonly used method of subjective analysis is the mandibular cortical index (MCI), introduced by Klemetti for the first time [2]. This index classifies the appearance of the lower mandibular cortex into three categories: $\mathrm{C} 1$ - the endosteal margin of the cortex is smooth and sharp on both sides; C2 - endosteal margin shows crescent defects and / or appears to form an endosteal cortical remnant on one or both sides; and the $\mathrm{c} 3$ cortical layer forms heavy endosteal cortical residues and is clearly porous speciffic for pacients with osteoporosis $[3,4]$.

The mandible cortical width (MCW) is the thickness of the mandible in the area ofthe mental foramen, which is a quantitative index. It can also be used to evaluate bone quality [5].

According to Benson et al. [6], mandibular panoramic index (PMI) is the thickness of the lower jaw cortex in the area of mental foramen. It can also be used to evaluate bone quality.

For evaluating the ramus height we evaluated: maxim coronoid height, maxim condylar height, ramus projective height, ramus height and condilar height.

Antegonial index (AI) is the measuring of the cortical width in the region anterior to the gonion at a point identified by extending a "best fit" line on the anterior border from the ascending ramus down to the lower border of the mandible [7].

The gonial index is the thickness of the lower jaw cortical, measured at half the angle between the lines tangent to the posterior edge of the branch and to the lower part of the lower jaw, which has a normal value higher than 1.2 [8].

Gonial angle (GA): was assessed by drawing a line tangent to the lower edge of the mandible and another line tangent to the posterior edge of the ascending frame of the mandible, proposed by Mattila et al. [9]. The intersection of these lines forms the gonial angle .
Antegonial angle (AA) is formed by two lines drawn parallel to the opposite area which intersected the deepest point of the antegonial notch [9].

\section{AIM}

The aim of this case report is to present a single patient case superimposed on the literature knowledge in regard to mophometric mandibular variations observed on dental panoramic radiography and used to identify patients with low BMD.

The informed consent was obtained prior to the start of the study. All records, documents, X-rays and case report forms were confidential. Personal data, such as a person's name or any identifiable data, is not retrieved to protect the confidentiality of the data. Only the chief investigator and the investigating money had access to the records. The study was evaluated by the Board of the Blident Help dental clinic and approved as low level negligible risk human research. The analysis and data processing were completed using SPSS 20.0. The two radiographs were taken with the same panoramic unit Instramentarium ${ }^{\circledR}$ Model OP 30, Tuusula, Finland considering standard exposure parameters $(73 \mathrm{Kv}, 10 \mathrm{~mA}, 10 \mathrm{sec}$, total infiltration $2.5 \mathrm{~mm} \mathrm{AL}$, focal spot $0.3 \mathrm{~mm}$ and magnification factor $1: 1.1)$. The pacient positioning for radiography wes made by the same person. The magnification compensation was performed using the magnification factor of $10 \%$ provided by the manufacturer (Cliniview 10.0). The measurements for each panoramic radiograph were made by a single investigator. Cliniview 10.0 was used ti digitally trace lines on the panoramic radiographs.

\section{CASE PRESENTATION}

A 62 years old female patient reported to the Blident Help Dental Clinic, for specific visits and treatments in octomber 2017 and in november 2020,3 years apart. At the second visit the pacient reported a $16.66 \%$ weight loss in the last year. (from $60 \mathrm{~kg}$ to $50 \mathrm{~kg}$ ). Patient associated affections are osteoporosis and cardiovascular disease under specific treatment. Based on the digital panoramic radiography and DXA measurement, an osteoporosis evaluation with radiomorphometric indices was performed in an effort to increase the dentists role for detecting the potential osteoporosis patients. 
We observed a decrease of body mass index from 21.09 to 18.18 after these 3 years, including the pacient from normoponderal to subponderal cathegory. From Bone Mineral density measurements, T score for lumbar spine (L1-14) decreased from -2.1 (in 2017) to -3.1 (2020) and T score for left femur decreased from -0.8 to -1.1 .

After morphometric measurements on the panoramic radiography we observed that the values for maximum condylar height, maximum coronoid height, projective height of the mandibular ramus, minimum ramus breadth and antegonial angle are higher on both sides. The values decreased for gonial angle, gonial index, MCW, superior and inferior mental height and panoramic mandibular indices on both sides. Bigonial distance dicreased from 153.4 (in 2017) [figure 1] to 150.3 (in 2020) [figure 2]. Mandibular cortical index also changed from C2 category in 2017 to C3 category in 2020.

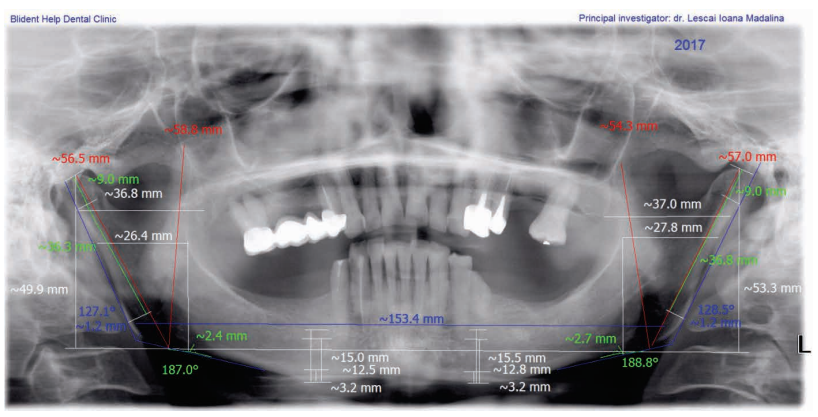

FIGURE 1. Patient panoramic radiography from 2017

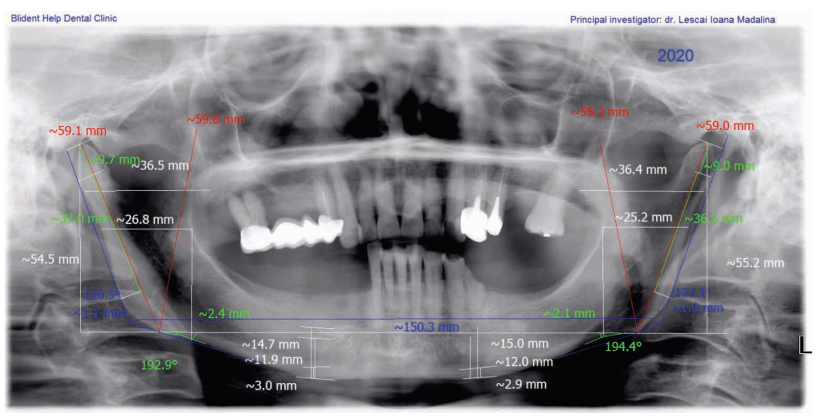

FIGURE 2. Patient panoramic radiography from 2020

There is an opposite trend of evolution between right and left part of the condylar height, ramus height and antegonial index: on one part the values are increasing and on the other part are decreasing [table 1].

\section{DISCUSSIONS}

Osteoporosis is a disease that causes loss of bone mass or strength results in fractures due to
TABLE 1. Values of the radiomorphometric indices in 2017 compared to 2020

\begin{tabular}{|l|l|l|l|l|}
\hline & 2017 & 2020 & 2017 & 2020 \\
\hline & right side & right side & left side & left side \\
\hline $\begin{array}{l}\text { Maximum condylar } \\
\text { height }\end{array}$ & 56.5 & 59.1 & 57 & 59 \\
\hline $\begin{array}{l}\text { Maximum coronoid } \\
\text { height }\end{array}$ & 58.8 & 59.6 & 54.3 & 56.6 \\
\hline Projective height & 49.7 & 54.5 & 53.3 & 55.2 \\
\hline $\begin{array}{l}\text { Maximum ramus } \\
\text { breadth }\end{array}$ & 36.8 & 36.9 & 37 & 36.4 \\
\hline $\begin{array}{l}\text { Minimim ramus } \\
\text { breadth }\end{array}$ & 26.8 & 26.4 & 27.8 & 25.2 \\
\hline Condylar height & 9.3 & 9.7 & 9 & 9 \\
\hline Ramus height & 36.3 & 37 & 36.8 & 36.5 \\
\hline Gonial angle & 127.1 & 126.5 & 128.5 & 127.1 \\
\hline Gonial index & 1.2 & 1.1 & 1.2 & 1 \\
\hline Antegonial angle & 187 & 192.9 & 188.8 & 194.4 \\
\hline Antegonial index & 2.4 & 2.4 & 2.7 & 2.1 \\
\hline $\begin{array}{l}\text { Superior mental } \\
\text { height }\end{array}$ & 15.4 & 14.7 & 15.5 & 15 \\
\hline $\begin{array}{l}\text { Infertior mental } \\
\text { height }\end{array}$ & 12.5 & 11.9 & 12.8 & 12 \\
\hline MCW & 3.2 & 3 & 3 & 2.9 \\
\hline PMI & 0.229 & 0.226 & 0.226 & 0.215 \\
\hline PMI superior & 0.208 & 0.204 & 0.206 & 0.193 \\
\hline PMI inferior & 0.256 & 0.252 & 0.25 & 0.242 \\
\hline
\end{tabular}

fragility. Therefore, the characteristic feature of this bone disease is the gradual reduction of bone density, which makes the patient more susceptible to fractures. The most common fractures are at the spine level and long bones [10]. Hormonal disorders, osteoporosis, osteopenia, recurrent pregnancy and lactation all affect bone shape and thickness $[11,12]$. Comparing women under 50 years of age for ramus height and bone density, Larhen et al. and Ali et al. $[13,14]$ showed that female postmenopausal decline had an effect on the mandible in this area.

Bhatnagar et al. [15] also showed a significant link between the level of erosion at the mandibular cortex and bone mass density. Panoramic radiography has $96 \%$ efficiency and $60 \%$ sensitivity in the assessment of osteoporosis, indicating that it is an effective control tool for osteoporosis.

In this study the pacient MCI index changed from $\mathrm{C} 2$ to $\mathrm{C} 3$ with a decreasing of the $\mathrm{T}$ score at the lumbar spine. Mansour et al. [16] found a significant association between MCI and bone mass density in lumbar spine. Patients classified as C3 in the MCI had the lowest BMD, followed by $\mathrm{C} 2$ and $\mathrm{C}$.

Kim et al. [17] found that the morphological changes in the mandibular cortical bone for the 
postmenopausal women were associated with BMD regardless of age, height and weight. Khojastehpour et al. [18] showed a significant relationship between mandibular cortical shape and age. As evidenced by Govindraju and Chandra [19], the risk for patients classified as $\mathrm{C} 2$ and $\mathrm{C} 3$ increased with age. In our case there were 3 years difference. This may be considered when assessing the postmenopausal women for osteoporosis.

Our pacient had a lowering in MCW value from 3.2 to 3 (on the right side) and from 3.2 to 2.9 on the left side. In postmenopausal women there are studies that showed a significant association between thin MCW and low BMD. In these cases the cortical thickness in the osteopenic / osteoporotic group is lower than that of the normal group [18,20,21]. Shakeel et al. [22] showed a positive relationship between $\mathrm{MCW}$ and BMD. Ferreira Leite et al. [23] showed that MCW was positively correlated with bone and neck density. These findings corespond with our results.

Our postmenopausal pacient had a decline in $\mathrm{MCW}$ values, from 3.2 to 2.9. Although the BMD T score for left femur and Spine L1-L4 lowered in these 3 years, the MCW values remained higher than 2.7. This was in agreement with Nagi et al. [24] who found the mandibular cortical to be lower than $3 \mathrm{~mm}$ (threshold to differentiate normal) on panoramic radiographs of women with low BMD. For Kim et al. [17] the mean MCW of menopausal women was $2.7 \mathrm{~mm}$, whereas the average $\mathrm{MCW}$ value for osteoporosis was $2.22 \mathrm{~mm}$ when a woman was diagnosed with osteoporosis. Khojastehpour et al. [18] and Kim et al. [17] showed that age was associated with MCW.

In a recent study, Vijay et al. [25] in addition to MI and MCI assessment, considered indices that are generally not compared such as gonial angle, antegonial angle, antegonial index. Results showed

\section{REFERENCES}

1. Chole RH, Patil RN, Balsaraf Chole S, Gondivkar S, Gadbail AR, Yuwanati MB. Association of mandible anatomy with age, gender, and dental status: a radiographic study. ISRN Radiol. 2013 Dec 18;2013:453763.

2. Klemetti E, Kolmakow S. Morphology of the mandibular cortex on panoramic radiographs as an indicator of bone quality. Dentomaxillofac Radiol. 1997 Jan;26(1):22-5.

3. Larheim TA, Svanaes DB. Reproducibility of rotational panoramic radiography: mandibular linear dimensions and angles. Am J Orthod Dentofacial Orthop. 1986 Jul;90(1):45-51. that Antegonial Index was significantly higher in normal patients (>3.2) compared with people with small bone mass (osteoporosis and osteopenia). Our pacient had a decreased value for antegonial index at the first visit (2.4 and 2.7). This could mean that antegonial index could be used as a prediction index for osteoporosis.

Dur-e-Shahwar et al. [26] found no significant change on panoramic radiographs for ramus height and ramus breadth. In contrast, Abu-Taleb et al. [27] found that coronoid ramus height was the only statistically significant predictor of age. In our study, projective mandibular height, maximum condylar height, projective height and minimum cramus breadth increased with age. In contrast, maximum ramus ramus breadth showed inconsistency in variations between left and right measurements.

To our knowledge, we couldn't find studies that have taken into account all the radiomorphometric indices for a comprehensive evaluation. Future research should be conducted to provide a representative sample that accurately reflects the variability of all these indices at the postmenopausal age for osteoporosis.

\section{CONCLUSIONS}

In this study, some effects of postmenopausal age on the ramus region were elucidated, and MCI, $\mathrm{MCW}$, antegonial index and bone density played an important role in determining its significance. It predicts higher risk of osteoporosis and bone loss, especially in postmenopausal women. Thus, as a routine dental examination, dentists could play an important role in diagnosing patients with low BMD and reffering them for bone densitometry and osteoporosis investigation.

Conflict of interest: none declared Financial support: none declared

4. Dutra V, Devlin H, Susin C, Yang J, Horner K, Fernandes AR. Mandibular morphological changes in low bone mass edentulous females: evaluation of panoramic radiographs. Oral Surg Oral Med Oral Pathol Oral Radiol Endod. 2006 Nov; 102(5):663-8.

5. Horner K, Devlin H, Harvey L. Detecting patients with low skeletal bone mass. J Dent. 2002 May;30(4):171-5.

6. Benson BW, Prihoda TJ, Glass BJ. Variations in adult cortical bone mass as measured by a panoramic mandibular index. Oral Surg Oral Med Oral Pathol. 1991 Mar;71(3):349-56. 
7. Ledgerton D, Horner K, Devlin H, Worthington $\mathrm{H}$. Radiomorphometric indices of the mandible in a British female population. Dentomaxillofac Radiol. 1999 May;28(3):173-81.

8. Bras J, van Ooij CP, Abraham-Inpijn L, Wilmink JM, Kusen GJ. Radiographic interpretation of the mandibular angular cortex: a diagnostic tool in metabolic bone loss. Part II. Renal osteodystrophy. Oral Surg Oral Med Oral Pathol. 1982 Jun;53(6):647-50.

9. Mattila K, Altonen M, Haavikko K. Determination of the gonial angle from the orthopantomogram. Angle Orthod. 1977 Apr;47(2):107-10.

10. Court-Brown CM, Caesar B. Epidemiology of adult fractures: $A$ review. Injury. 2006 Aug;37(8):691-7.

11. Ghosh S, Vengal M, Pai KM, Abhishek K. Remodeling of the antegonial angle region in the human mandible: a panoramic radiographic cross-sectional study. Med Oral Patol Oral Cir Bucal. 2010 Sep 1;15(5):e802-7.

12. Preston B, Al-Sehaibany F, Salem O. The morphology of the mandibular antegonial notches and facial symmetry. J Clin Pediatr Dent. 2002 Winter;26(2):155-60.

13. Larheim TA, Svanaes DB. Reproducibility of rotational panoramic radiography: mandibular linear dimensions and angles. Am J Orthod Dentofacial Orthop. 1986 Jul;90(1):45-51.

14. Ali IM, Yamada K, Hanada K. Mandibular antegonial and ramus notch depths and condylar bone change. J Oral Rehabil. 2005 Jan;32(1):1-6.

15. Bhatnagar S, Krishnamurthy V, Pagare SS. Diagnostic efficacy of panoramic radiography in detection of osteoporosis in postmenopausal women with low bone mineral density. J Clin Imaging Sci. 2013 Jun 6;3:23.

16. Mansour S, AIGhamdi AS, Javed F, Marzouk H, Khan EA. Panoramic radiomorphometric indices as reliable parameters in predicting osteoporosis. Am J Med Sci. 2013 Dec;346(6):473-8.

17. Kim OS, Shin MH, Song IH, Lim IG, Yoon SJ, Kim OJ, Lee YH, Kim YJ, Chung HJ. Digital panoramic radiographs are useful for diagnosis of osteoporosis in Korean postmenopausal women. Gerodontology. 2016 Jun;33(2):185-92.

18. Khojastehpour L, Afsa M, Dabbaghmanesh MH. Evaluation of Correlation between Width and Morphology of Mandibular Inferior
Cortex in Digital Panoramic Radiography and Postmenopausal Osteoporosis. Iran Red Crescent Med J. 2011 Mar;13(3):181-6.

19. Govindraju P, Chandra P. Radiomorphometric indices of the mandible - an indicator of osteoporosis. J Clin Diagn Res. 2014 Mar;8(3):195-8.

20. Passos JS, Gomes Filho IS, Sarmento VA, Sampaio DS, Gonçalves FP, Coelho JM, Cruz SS, Trindade SC, Cerqueira EM. Women with low bone mineral density and dental panoramic radiography. Menopause. 2012 Jun;19(6):704-9.

21. Hekmatin E, Ahmadi SS, Ataiekhorasgani M, Feizianfard M, Jafaripozve S, Jafaripozve N. Prediction of lumbar spine bone mineral density from the mandibular cortical width in postmenopausal women. J Res Med Sci. 2013 Nov;18(11):951-5.

22. Shakeel MK, Daniel MJ, Srinivasan SV, Koliyan R, Kumar JV. Comparative Analysis of Linear and Angular Measurements on Digital Orthopantomogram with Calcaneus Bone Mineral Density. J Clin Diagn Res. 2015 Jul;9(7):ZC12-6.

23. Ferreira Leite A, de Souza Figueiredo PT, Ramos Barra F, Santos de Melo N, de Paula AP. Relationships between mandibular cortical indexes, bone mineral density, and osteoporotic fractures in Brazilian men over 60 years old. Oral Surg Oral Med Oral Pathol Oral Radiol Endod. 2011 Nov;112(5):648-56.

24. Nagi R, Devi B K Y, Rakesh N, Reddy SS, Santana N, Shetty N. Relationship between femur bone mineral density, body mass index and dental panoramic mandibular cortical width in diagnosis of elderly postmenopausal women with osteoporosis. J Clin Diagn Res. 2014 Aug;8(8):ZC36-40.

25. Vijay G, Chitroda PK, Katti G, Shahbaz S, Baba I, Bhuvaneshwari. Prediction of osteoporosis using dental radiographs and age in females. J Midlife Health. 2015 Apr-Jun;6(2):70-5.

26. Dur-e-Shahwar R, Talat $Y$, Nabeel Q. Correlation of mandibular ramus height and width eith osteoporosis. Journal of Oral and Maxilofacial Radiology. 2017 Nov;5(2):40-45.

27. Abu-Taleb N, El Beshlawy D. (2015). Mandibular Ramus and Gonial Angle Measurements as Predictors of Sex and Age in an Egyptian Population Sample: A Digital Panoramic Study. Journal of Forensic Research. 2015 Jan;6:5. 